\title{
A Review of the Paper 'The Continuous Model of Culture: Modernity Decline- A Eurocentric Bias? An Attempt to Introduce an Absolute Value into a Model of Culture'
}

\section{Giorgi Kankava*}

An Independent Scholar, Tbilisi, Georgia, USA

*Corresponding author: Dr. Giorgi Kankava, An Independent Scholar, Tbilisi, Georgia, USA, Tel: +374 10 23-72-61; E-mail: gkankava@gmail.com

Received date: November 24, 2014, Accepted date: January 27, 2015, Published date: February 07, 2015

Copyright: () 2014 Kankava G. This is an open-access article distributed under the terms of the Creative Commons Attribution License, which permits unrestricted use, distribution, and reproduction in any medium, provided the original author and source are credited.

\section{The Continuous Model of Culture}

A model of culture, the continuous model of culture, presented by the paper is an attempt to work out solutions to several important issues as a matter of standing debates in human and social sciences. Given that it is a review of the paper, I am going to provide the reader with only some of its outcomes yet in their close connection with the three main aspects of the model's general approach to sociocultural being-the end-means and absolute value plus concept of reality approach to culture. It ascribes to culture more wide and fundamental meaning than cultural studies does, and by this, it stands closer to a strong program in cultural sociology [1]. The latter is striving for attributing the trait of autonomy to culture within a consistent theoretical framework, yet so far unsuccessfully. I suggest that this is possible only at the level of philosophizing-namely, via overcoming intellectualism marking the mainstream philosophical discourse of modern philosophy since its origination. According to the paper, arguing for cultural autonomy is incompatible with intellectualism, and introducing an absolute value into a cultural model supports the task. In addition, the three aspects of the approach are closely related. For example, an absolute value as such implies an ultimate end or wish relative to which everything else one could consider as a means or a challenge to it.

First, the model specifies the relations between a particular culture and its members. I relate an absolute value to the human person's secular metaphysical intention: She wants to be most of all, and this is her ultimate wish. By this framework, although biologically temporal, the human person satisfies her metaphysical intention by participating in the reproduction of her particular culture as its member and/or as a citizen of the respective nation-state. She does so despite the fact of the individual temporality of her life, for the realization of her metaphysical intention represents her greatest wish. In times of secularity, the power of the metaphysical reveals itself in an (additional) cultural self-reproduction of humans, with culture making's being their distinguishing characteristic; in other words, cultural reproduction implies humans' additional being with metaphysical perspective, displaying them as cultural, not just biological, beings. Therefore, a particular culture or a nation presents a human social group within which its members realize their metaphysical intention additionally by participating routinely in its additional reproduction according to their social roles or otherwise in extreme instances. The particular way of life established, kept and/or developed by its members is established, kept and developed by them to satisfy their formally identical metaphysical intentions jointly (in this and only in this sense I will use the expressions like a particular culture's ultimate wish, end etc. bellow) against the background of events producing the proximate environment meeting the members' metaphysical intention only by chance. A culture as a certain humanmade common way of life is enough for its bearers or followers to satisfy their metaphysical intention yet historically, here and now rather than universally. In this context, the model distinguishes between the meanings of culture and nature. The former is humanmade means to the ultimate wish, whereas the latter is always a readymade fact and as such conforms with the ultimate wish only by chance. Now consider too that in having been designed within their historical trajectories incidental to one another, particular cultures' ways of life, or means to the ultimate end, would meet the ultimate wishes of one another only by chance. Thus each would ascribe to one another the property of a natural fact. Thus particular cultures see one another as being part of nature due to the differences in their ways of life. This explains not only the fact of cultural alienation but also the one, related to the former, according to which, it takes a time for immigrants to reconcile their lifestyles with the host country's cultural way of life. Moreover, comparative literature study of cultures, a sample of which I presented in the paper, might provide the reader with the view that culture in itself is sewn from universal binaries or opposites. Nonetheless, during their historical trajectories of being, cultures are free to articulate the terms of the binaries independently of one another as the expression of their particular and individual cultural ways of life or cultural individuality, a matter to which I will return later when introducing a notion of particular culture's concept of reality. Accordingly, the differences among cultures would vary in extent; though they are always relative, they could be comparatively huge. Accordingly, the time of assimilation would also depend on the extent of similarity between cultures of the sending and the host countries. Moreover, imagine now a situation where immigrants are still enjoying realizing their metaphysical intention through their sending countries' cultural values but at once prefer to satisfy their socio-economic needs, being of relative, not absolute, value, in the host country. In that case, you will get socio-economic links across the nation states' boarders, globalization sociology is happy to announce as a new 'trans-national' cultural experience coupled with the notion of the so-called dual identities. The above situation modeling shows it out that actually, there is no the 'trans-' or the 'dual' at all but still the 'national' and the 'national identity' that characterize the border crossing

The model, too, specifies the relations among particular cultures within the wider culture system. As it was already specified, natural facts meet humans' ultimate wish to self-reproduce via human-made cultural means only by chance. This exposes the cultural narrative as demanding that humans re-create the universe into the state where metaphysical intention would be met a priori or constantly. This being condition I name the universal last state of culture, or using Leibniz's term, the best of all possible worlds. Unlike monadology, I suggest that 
human beings are engaged in building it by themselves through the routine cultural process. It presents the ultimate reality from the human person's standpoint, and it is this existential state to which she ascribes an absolute value. The comparative literature study, too, suggests that particular cultures, however different they could be, always refer to the same state of the ultimate reality as the universal target of their ultimate end. Accordingly, particular cultures seem still particular "humankinds" in dialogue about and competition for formulating and building the best of all possible worlds. According to this model, culturally, humankind is still the eclectic system of particular cultures (the culture system), it one should still realize its real nature of the universe (re-) Maker. A particular culture represents a relative (human) reality but already marked subjectively with metaphysical prospect 'pointing' at the ultimate reality as the referent.

In this context, the paper, too, distinguish between instrumental and ideal-symbolical functions of particular culture. Its instrumental function is a historically relevant particular and individual means to realizing the ultimate end of building the best of all possible world additionally, including the particular culture's work ethic, socioeconomic structure, political institutions, and ideology. In being a member of particular culture, the human person realizes her metaphysical intention by participating in the building. On the other hand, only the participation in the process humanizes a human individual. Particular culture's this more 'material' content also performs the symbolical function. It serves as a sign of the ultimate reality or the best of all possible worlds, the referent. Although the referent is universal, the access to it is possible through historically created forms of its realization as particular cultures. This is an additional argument explaining why particular culture and cultural particularism is so steady; as regards its followers, the same question would sound like this-why it is so attractive in their eyes. In general, from this frameworks' standpoint, it is not an easy task to reconcile particular cultures existential interests, which can and often does lead them to play zero sum game. However, just claiming that 'cultural particularism is obsolete, violent, oppressive' etc. is no way out of the issue. The claim would remain and does remain without reply. The best way to solve the problem is to get to the essence of the question about why cultural particularism is still attractive to their members despite violence, disorder, crime etc. often accompanying it. The answer with which this model provides one is that the instrumental function of culture such as a particular culture's way of life, cultural values etc. refer to the ultimate reality as a sign refers the referent, a function which in pre-modern times had been performed mainly by religion and the church. One would hardly give up one's only connection to a reality, the cost of which one estimates subjectively at an absolute value because of a claim, given that one does not yield even to the possibility of becoming a victim of the accompanying disorder and violence oneself.

Furthermore, overcoming intellectualism via introducing absolute value and end-means approach into social science leads to the understanding that social structure or society represents particular cultural community's historically effective means to the ultimate end of self-reproducing additionally with metaphysical perspective against the ready-made cultural and/or natural environment. Cultures do this diversely, which on the other hand, provides them with the opportunity to learn from one another the means in the form of those that are historically relevant to their self-reproduction in the process. In this framework, this explains the relation between society and culture, and the facts of cultural diffusion and 'modernization, respectively.
Accordingly, in this model, there is no place for the structureagency 'dichotomy', from which 'traditional' modern science suffers essentially. To an 'ideal' competent citizen, it would be obvious that historically effective or relevant socio-cultural structure presents historically relevant or rational means to her ultimate wish of realizing her metaphysical intention. Such a human agent would see sociocultural structure as an existential teleological mechanism that limits choices available to the agent to ones that would fulfill her ultimate wish for additional existence stably vis-a-vis to recurrent ready-made facts harmonizing with it only occasionally. Hence, here, one has no reason for debating the supremacy of agency or structure in shaping human behavior, as structure serves as an agent's means to the agent's ultimate wish. Additionally, the deeper sense of the social construction of reality [2] would sound like this: Humans are engaged in reconstructing relative reality built constantly by the ready-made existential projects not aligned yet with humans' one until it coincides with the best of all possible worlds, the ultimate reality.

The proposed pattern of thought argues for cultural autonomy as well. As the symbolical function interprets the ready-made facts in terms of a potential means or challenge, the meaning of things, not things themselves, gets humans to react respectively through their joint action. Considering the empirical content of things would be necessary for the joint action to be capable of serving human agent's ultimate goal of additional presence with metaphysical perspective. Correspondingly, cultural autonomy would imply that the idealsymbolical function of culture is the subjective driver of a human society's additional existence with metaphysical perspective.

The third aspect of the approach-a concept of reality-is also related to an absolute value notion. It presents an account of reality shared by cultural community members. A concept of reality expresses their shared view on existence extracting what they consider important in it. The core of the importance is likely to be linked with their presence in the being process. In being existentially biased, it has nothing to do with a scientific account of it; though, it is still necessary for cultural practice. Cultural values and traditions link to the concept of reality. It has to do with the universal binaries the way in which a particular culture has articulated them historically, forming its cultural individuality. According to the comparative literature study of cultures, particular culture's cultural individuality shapes its approach to reality. Once a particular culture has articulated the terms of the universal binaries historically in a specific-to-it way, it tends to be reluctant to change it by replacing it with their opposites. A culture's concept of reality proper represents as well as preserves its cultural individuality. For example, the opposites individual or collectivistic tend to characterize cultures' concepts of reality more or less stably so that we have the notions of collectivistic and individualistic cultures described by traditional modern social science. However, within it, an answer to the why question about the cause for their stability is not much evident. Roughly, unilineal sociocultural evolution expects that as a matter of development, all of them will have become individualistic eventually. However, this model expects something rather different. Historically shaped concepts of reality represent not just their holders' worldview but also particular and individual pattern for building the best of all possible worlds. A concept of reality conserves the basics, either an individual or collectivistic (general), for example, of a particular culture's views on what the best of all possible worlds should be like. That is to say, they present its particular and individual norms or rules to build it. In this sense, they tend to be 'conservative'-loyal to their own above-mentioned pattern. In being 'biased' against each other, they are critical to one another as well, so that eventually, the 
Citation: Kankava G (2015) A Review of the Paper 'The Continuous Model of Culture: Modernity Decline- A Eurocentric Bias? An Attempt to Introduce an Absolute Value into a Model of Culture'. Arts Social Sci J 6: 93. doi:10.4172/2151-6200.100093

Page 3 of 3

concepts of reality compete with each other in building the cultural process in the culture system, which contributes to a dialectical model of progress. 'Wining' norms and laws of building socio-economic and political structure outcompete others as less effective in the given historical 'moment', in that for particular cultures, not to learn and use them expands their costs for additional self-reproduction in the given historical period. From this standpoint, in the paper, I modeled the mechanism of the current success of state capitalism, with modernization theory so far vague about the matter.

The comparative literature study revealed too that actually, modernization theory, as well as sociocultural evolution in general, is in turn, also involved in prescribing recipes for building the best of all possible worlds, seen as modernity exclusively. However, this model's prediction about the topic differs from theirs. The case is modernity's concept of reality. Modernity's intellectualism together with its nominalism and utilitarianism reduces value judgment to fact, absolute value to relative value, and society to individual in which case, it cannot balance politics and economics, which is the failure of the modernity project based among other things on the division between politics and economics. The prediction is that if nothing is changed, it inevitably will have ended up in oligarchy disaster. According to this model, economics, serving the needs of relative value, is a necessary means to nation state' politics, for the latter presents the ultimate means to the self-reproduction of a particular cultural community in its interaction with its environment as the culture system and/or nature. Unlike modernity, 'collectivistic' or 'traditional' cultures, owing to their concepts of reality, would see the cultural community rather than the individual as the ultimate measure of human existence certainty. Accordingly, they would be less sensitive to the ugly aspects of capitalism in advance. While learning 'wining' free market economy from modernity, they would have the relative advantage in keeping the separation between economics, based on an individual's self-interest, and politics, in times when modernity has failed to preserve it. The model finds modernity's concept of reality to be involved in "methodological" intellectualistic reductionism, characterizing it since the empiricism/rationalism origination. Systematically confusing the universal oppositions in a Eurocentric manner, intellectualism becomes a contributing factor in unfolding post-modernity.

This framework, too, provides the reader with the conceptions of interpretative qualitative research and interdisciplinary. The latter suggests a method for studying cultures as the comparative literature study of cultures, engaged in extracting a concept of reality by the culture of interest.

\section{References}

1. Alexander JC, Smith P (2001) The strong program in cultural sociology. Center for Cultural Sociology.

2. Burke P (2002) History and social theory. (trans: Ladaria, N.). Tbilisi: Logos. 